Danish computer workers. Scand I Work Environ Health 2004;30:399-409.

8 Lassen CF, Mikkelsen S, Kryger Al, et al. Elbow and wrist/hand symptoms among 6,943 computer operators: a 1-year follow-up study (the NUDATA study). Am J Ind Med 2004:46:521-33.

9 Tornqvist EW, Kilbom $\AA$, Vingård $E$, et al. The influence on seeking care because of neck and shoulder disorders from work-related exposures. Epidemiology $2001 ; 12: 537-45$

10 Rempel DM, Krause N, Goldberg R, et al. A randomised controlled trial evaluating the effects of two workstation interventions on upper body pain and incident musculoskeletal disorders among computer operators. Occup Environ Med 2006:63:300-6

11 Gerr F, Marcus M, Monteilh C, et al. $A$ randomised controlled trial of postural interventions for prevention of musculoskeletal symptoms among computer users. Occup Environ Med 2005:62:478-87.

12 Aarås A, Horgen G, Ro O, et al. The effect of an ergonomic intervention on musculoskeletal psychosocial and visual strain of VDT data entry work: the Norwegian part of the international study. Int J Occup Safety Ergon 2005; 11:25-47.

\section{Health risks from mobile phone base stations}

\section{Coggon}

\section{Commentary on the paper by Hutter et al (see page 307)}

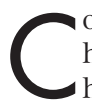
oncerns about possible adverse health effects of mobile telephony have focused mainly on the risk of brain tumours in users of mobile phones, but other types of illness have also been linked with the technology. In particular, several epidemiological surveys have suggested associations with non-specific complaints such as headache, tiredness, sleep disturbance, loss of memory, and dizziness. These findings, which echo reports of illness associated with other types of radiofrequency (RF) radiation, ${ }^{1}$ relate not only to use of mobile phones, ${ }^{2-4}$ but also to residence near to mobile phone base stations. ${ }^{5}$

Further evidence on the latter is provided in a paper by Hutter et al in this issue. ${ }^{6}$ They found that symptoms such as headache, fatigue, and difficulty in concentration were more common in people with higher potential exposures to radiation from nearby base stations, and that the association remained significant after adjustment for various possible confounding factors, including regular personal use of mobile phones.

Given these new findings, how strong is the evidence that residential proximity to mobile phone base stations causes illness, and if it does, what is the underlying mechanism?

A weakness of earlier studies was that both exposure and symptoms were ascertained by questioning participants. As a consequence, risk estimates may have been inflated through biased recall. The study by Hutter et al avoided this problem by estimating exposures from measurements of RF fields in subjects' bedrooms. The method was still not ideal. For practical reasons, measurements could only be short term, and may not have captured the full range of temporal variation at the monitoring site. Moreover, participants spent only part of their time at home, and their exposures at other locations may have been quite different. In general, however, the effects of any resultant misclassification of exposures would be to bias risk estimates towards the null, and not to give spurious associations.

A more important limitation, given the large number of health outcomes examined in the study, is the possibility that some associations occurred by chance. Concerns about this are reduced insofar as positive associations were observed with many of the symptoms examined. However, further confirmation is needed before an elevated risk of such symptoms can be regarded as established.

Even if there were a true association, it would not necessarily imply a toxic effect of RF radiation. Currently there is no known biophysical mechanism by which low level exposures could cause toxicity in a substantial proportion of the general population (the excess prevalence of many symptoms in the Hutter et al study was more than 15\%), when the same symptoms do not appear to be a problem in many people who regularly use mobile phones for prolonged periods with exposures to the head that are orders of magnitude higher. An alternative possibility is that illness occurs as a psychologically mediated response to a perceived hazardous exposure. In this respect, it is notable that similar symptoms have also been reported in relation to a diverse range of chemical exposures, again without any demonstrable underlying toxicological mechanism.

Hutter and colleagues tried to address this possibility by adjusting risk estimates for individual beliefs about health risks from base stations, but the fact that associations persisted after this adjustment does not exclude a psychological origin for the symptoms. To give an extreme example, if everyone in the study had identical beliefs, the adjustment would have no impact on risk estimates whatsoever, but risk could still depend importantly on people's beliefs and expectations.

Another way to explore pathogenesis is by testing the effects of exposure experimentally in blinded subjects, an approach that will be valid provided that effects are relatively immediate and do not persist for a long time after last exposure. One such study found a significant reduction in wellbeing with exposure to RF fields similar to those produced by a UMTS (universal mobile telecommunications system) base station, both in subjects who had previously indicated symptoms that they attributed to base stations, and also in healthy volunteers. ${ }^{8}$ However, there was no parallel effect from GSM (global system for mobile telecommunication) type fields, and in an earlier experiment by Hiatenen and colleagues, ${ }^{9}$ the incidence of symptoms in subjects who believed that they were sensitive to radiation from mobile phones was higher during periods of sham than of real exposure. Interpretation of these inconsistencies can only be resolved by further research.

Meanwhile, decisions on the siting of base stations must be made in a context of uncertainty. Hutter and colleagues propose that as a precautionary measure, base stations should be positioned in a way that minimises the exposure of neighbours, and this seems a sensible 
policy where other considerations are equal. However, the suspicion of a toxic effect is relatively low, and there may be disadvantages in over-precaution. Evidence is emerging that prior beliefs about the risks from modern technology are an important predictor of symptoms from perceived exposures. ${ }^{10}$ Thus, by distorting perceptions of risk, disproportionate precaution might paradoxically lead to illness that would not otherwise occur.

Occup Environ Med 2006;63:298-299.

doi: 10.1136/oem.2005.025510

Correspondence to: Prof. D Coggon, MRC Epidemiology Resource Centre, Southampton General Hospital, Southampton SO16 6YD, UK; dnc@mrc.soton.ac.uk

Competing interests: none declared

\section{REFERENCES}

1 National Radiological Protection Board. Health effects from radiofrequency electromagnetic fields. Chilton: National Radiological Protection Board, 2003, 107-10 (Documents of the NRPB, Vol 14, No 2)

2 Chia S-E, Chia H-P, Tan J-S. Prevalence of headache among handheld cellular telephone users in Singapore: a community study. Environ Health Perspect 2000; 108: 1059-62.

3 Sandström M, Wilén J, Oftedal G, et al. Mobile phone use and subjective symptoms. Comparison of symptoms reported by users of analogue and digital mobile phones. Occup Med 2001;51:25-35.

4 Santini R, Seigne M, Bonhomme-Faivre $L$, et al. Symptômes rapportés par des utilasateurs de téléphones mobiles cellulaires. Pathol Biol (Paris) $2001 ; 49: 222-6$

5 Santini R, Santini P, Danze JM, et al. Enquête sur la santé de riverains de stations relais de téléphonie mobile: $I /$ Incidences de la distance et du sexe. Pathol Biol (Paris) 2002;50:369-73.
6 Hutter $\mathrm{H}-\mathrm{P}$, Moshammer $\mathrm{H}$, Wallner $\mathrm{P}$, et al. Subjective symptoms, sleeping problems, and cognitive performance in subjects living near mobile phone base stations. Occup Environ Med 2006:63:307-13

7 Coggon D. Occupational medicine at a turning point. Occup Environ Med 2005; 62:281-3.

8 Zwamborn APM, Vossen SHJA, van Leersum BJAM, et al. Effects of global communications system radiofrequency fields on well being and cognitive functions of human subjects with and without subjective complaints, TNO report, FEL-03-C148. The Hague, 2003

9 Hietanen $M$, Hämäläinen A-M, Husman T. Hypersensitivity symptoms associated with exposure to cellular telephones: no causal link. Bioelectromagnetics 2002;23:264-70.

10 Petrie KJ, Broadbent EA, Kley N, et al. Worries about modernity predict symptom complaints after environmental pesticide spraying. Psychosom Med 2005;67:778-82.

\section{Clinical Evidence-Call for contributors}

Clinical Evidence is a regularly updated evidence-based journal available worldwide both as a paper version and on the internet. Clinical Evidence needs to recruit a number of new contributors. Contributors are healthcare professionals or epidemiologists with experience in evidence-based medicine and the ability to write in a concise and structured way.

Areas for which we are currently seeking contributors:

- Pregnancy and childbirth

- Endocrine disorders

- Palliative care

- Tropical diseases

We are also looking for contributors for existing topics. For full details on what these topics are please visit www.clinicalevidence.com/ceweb/contribute/index.jsp

However, we are always looking for others, so do not let this list discourage you.

Being a contributor involves:

- Selecting from a validated, screened search (performed by in-house Information Specialists) epidemiologically sound studies for inclusion.

- Documenting your decisions about which studies to include on an inclusion and exclusion form, which we keep on file.

- Writing the text to a highly structured template (about 1500-3000 words), using evidence from the final studies chosen, within 8-10 weeks of receiving the literature search.

- Working with Clinical Evidence editors to ensure that the final text meets epidemiological and style standards.

- Updating the text every 12 months using any new, sound evidence that becomes available. The Clinical Evidence in-house team will conduct the searches for contributors; your task is simply to filter out high quality studies and incorporate them in the existing text.

If you would like to become a contributor for Clinical Evidence or require more information about what this involves please send your contact details and a copy of your CV, clearly stating the clinical area you are interested in, to CECommissioning@bmigroup.com.

\section{Call for peer reviewers}

Clinical Evidence also needs to recruit a number of new peer reviewers specifically with an interest in the clinical areas stated above, and also others related to general practice. Peer reviewers are healthcare professionals or epidemiologists with experience in evidence-based medicine. As a peer reviewer you would be asked for your views on the clinical relevance, validity, and accessibility of specific topics within the journal, and their usefulness to the intended audience (international generalists and healthcare professionals, possibly with limited statistical knowledge). Topics are usually 1500-3000 words in length and we would ask you to review between 2-5 topics per year. The peer review process takes place throughout the year, and out turnaround time for each review is ideally 10-14 days.

If you are interested in becoming a peer reviewer for Clinical Evidence, please complete the peer review questionnaire at www. clinicalevidence.com/ceweb/contribute/peerreviewer.jsp 